QA: NA

REV 03

December 2004

\title{
SOURCE OF BURNUP VALUES FOR COMMERCIAL SPENT NUCLEAR FUEL ASSEMBLIES
}

Prepared for:

U.S. Department of Energy

Office of Civilian Radioactive Waste Management

Office of Repository Development

P.O. Box 364629

North Las Vegas, Nevada 89036-8629

Prepared by:

Bechtel SAIC Company, LLC

1180 Town Center Drive

Las Vegas, Nevada 89144

Under Contract Number

DE-AC28-01RW12101 


\section{Source Of Burnup Values For Commercial Spent Nuclear Fuel Assemblies}

\section{Executive Summary}

Waste packages are loaded with commercial spent nuclear fuel (SNF) that satisfies the minimum burnup requirements of a criticality loading curve. The burnup value assigned by the originating nuclear utility to each SNF assembly (assigned burnup) is used to load waste packages in compliance with a criticality loading curve. The burnup provided by a nuclear utility has uncertainties, so conservative calculation methods are used to characterize those uncertainties for incorporation into the criticality loading curves. Procedural safety controls ensure that the correct assembly is loaded into each waste package to prevent a misload that could create a condition affecting the safety margins. Probabilistic analyses show that procedural safety controls can minimize the chance of a misload but can not completely eliminate the possibility. Physical measurements of burnup with instrumentation in the surface facility are not necessary due to the conservative calculation methods used to produce the criticality loading curves.

The reactor records assigned burnup of a commercial SNF assembly contains about two percent uncertainty, which is increased to five-percent to ensure conservatism. This fivepercent uncertainty is accommodated by adjusting the criticality loading curve. Also, the record keeping methods of nuclear utilities are not uniform and the level of detail required by the NRC has varied over the last several decades. Thus, some SNF assemblies may have assigned burnups that are averages for a batch of assemblies with similar characteristics. Utilities typically have access to more detailed core-follow records that allow the batch average burnup to be changed to an assembly specific burnup. Alternatively, an additional safety margin is incorporated into the criticality loading curve to accommodate SNF assemblies with batch average burnups or greater uncertainties due to the methodology used by the nuclear utility.

The utility records provide the assembly identifier, initial ${ }^{235} \mathrm{U}$ enrichment, and time of discharge from the reactor as well as the assigned burnup, but the distribution of burnup axially along the assembly length is not provided. The axial burnup profile is maintained within acceptable bounds by the operating conditions of the nuclear reactor and is calculated during preparations to reload a reactor, but the actual burnup profile is not measured. The axial burnup profile is important to the determination of the reactivity of a waste package, so a conservative evaluation of the calculated axial profiles for a large database of SNF has been performed. The product of the axial profile evaluation is a profile that is conservative. Thus, there is no need for physical measurement of the axial profile.

The assembly identifier is legible on each SNF assembly and the utility records provide the associated characteristics of the assembly. The conservative methodologies used to determine the criticality loading curve for a waste package provide sufficient margin so that criticality safety is assured for preclosure operations even in the event of a misload. Consideration of misload effects for postclosure time periods is provided by the criticality Features, Events, and Processes (FEPs) analysis.

The conservative approaches used to develop and apply the criticality loading curve are thus sufficiently robust that the utility assigned burnup is an adequate source of burnup values, and additional means of verification of assigned burnup through physical measurements are not needed. 
Source Of Burnup Values For Commercial Spent Nuclear. Fuel Assemblies

\section{Glossary}

Assigned burnup - the SNF burnup used in the comparison against the criticality loading curve, initially assigned by the originating utility but modified if necessary by DOE

Axial profile - the variation of burnup as a function of axial position along a SNF assembly

BWR - Boiling water reactor

Calculated burnup - the SNF burnup calculated by a core-follow code

Core-follow code - a reactor physics code set that allows each assembly in a reactor core to be analyzed to determine the burnup at the end of a reactor cycle

MCNP - Monte Carlo N-Particle computer code, used to calculate the reactivity ( $k_{\text {effective}}$ ) of waste packages

Misload - loading of an incorrect commercial SNF assembly into a waste package

PWR - Pressurized water reactor

Reactor record(s) - the records of all fuel assemblies loaded into a commercial PWR or BWR reactor, including assembly identifier, initial enrichment, and assigned burnup

Required minimum burnup - for a given initial fuel enrichment, the minimum burnup that will satisfy the criticality loading curve

SNF - Spent nuclear fuel 


\section{Source Of Burnup Values For Cömmercial Spent Nuclear Fuel Assemblies.}

\section{Purpose}

This document describes the Yucca Mountain Project's (YMP's) position on the source of burnup values to be used in burnup credit evaluations. It also provides a description of the methodology to be used in estimating uncertainties associated with the burnup values.

These issues are associated with key technical issue (KTI) agreement PRE 7.01. The KTI agreement for PRE 7.01 is as follows: "Provide an update to the Pre-Closure Criticality Analysis Report Process Report. DOE agreed to provide the report. The report will be available in FY2003."

At the time KTI Agreement PRE 7.01 was prepared, the U.S. Nuclear Regulatory Commission (NRC) had specifically requested information regarding the U.S. Department of Energy's (DOE) approach on the use of burnup credit for Spent Nuclear Fuel (SNF) in criticality safety analyses. It had been DOE's intent to include this information in the Preclosure Criticality Analysis Process Report. Changes in project plans and schedules prevented DOE from doing this. The DOE position was initially presented in the Disposal Criticality Analysis Methodology Topical Report, YMP/TR-004Q REV 02 (YMP 2003). The Yucca Mountain Repository Safety Analysis Report includes further discussion of the criticality control measures to be implemented at the repository.

\section{Descriptions of Issues}

The YMP is using burnup credit for postclosure criticality performance evaluations of the commercial SNF waste packages (YMP 2003) and as a defense in depth measure for preclosure criticality safety in the waste package. The burnup of a nuclear fuel assembly is a key input parameter in determining the isotopic concentrations that permit taking credit for a reduction in the potential for nuclear criticality (i.e., burnup credit). Burnup is a measure of the exposure of a nuclear fuel assembly in a reactor core during power operations and is directly related to the net depletion of fissile material and production of fission products. Burnup values are usually expressed in units of MWd/MTU (megawatt days of in-core exposure per metric ton of uranium initially loaded into the assembly). Calculated burnup values are determined from calculations that are verified through incore physical measurements throughout the assembly's irradiation history. A calculated burnup value becomes a part of the reactor records for SNF when it is assigned to each discharged assembly.

The NRC staff has previously taken the position that "...credit for fuel burnup may be taken only when the amount of burnup is confirmed by physical measurements that are appropriate for each type of fuel assembly..." as reflected in Regulatory Guide 3.71 (NRC 1998) and in Open Item 1 in the Safety Evaluation Report to the Disposal Criticality Analysis Methodology Topical Report (Reamer 2000, p. 77). NUREG-1762 Integrated Issue Resolution Status Report (NRC 2002a, p. 2.1.7-35) indicates that, although the NRC staff agrees with DOE staff that reactor records are a more accurate source of fuel assembly burnup data than physical measurements (Reamer and Gil 2001), "...its current position, however, is that measurements are needed to verify the burnup indicated by reactor records..." 


\section{Source Of Burnup Values For Commercial Spent Nuclear Fuel Assemblies}

Specific NRC staff concerns that are addressed in this report include:

1. The quality and accuracy of the assigned burnups are not uniform for all utilities and for all years of reactor operation;

2. The criticality safety methodology must take into account the criticality effect of nonuniform burnup as a function of position along the axis of the fuel assembly.

3. A misload of a waste package cannot be ruled out, and the criticality effects of a misload must be accounted for by the preclosure criticality safety methodology.

\section{Waste Package Loading Procedures}

Waste packages are loaded with commercial spent nuclear fuel (SNF) that satisfies the minimum burnup requirements of a criticality loading curve. An assembly identifier is legible on each SNF assembly, and the utility records provide the associated characteristics of the assembly, including heat source and assigned burnup Only SNF that has an assigned burnup greater than the required minimum burnup may be loaded into a standard waste package. SNF that does not posses the required minimum burnup must be loaded into a waste package that contains additional criticality control capabilities. The burnup value assigned by the originating nuclear utility to each SNF assembly (assigned burnup) is used to load waste packages in compliance with a criticality loading curve. The assigned burnup has uncertainties, so conservative calculation methods are used to characterize those uncertainties for incorporation into the criticality loading curves. Typically, an additional margin is added to the required minimum burnup of a criticality loading curve for each identified source of uncertainty in the assigned burnup.

The utility records provide the assembly identifier, initial ${ }^{235} U$ enrichment, and time of discharge from the reactor as well as the assigned burnup, but the distribution of burnup axially along the assembly length is not provided. The axial burnup profile is maintained within acceptable bounds by the operating conditions of the nuclear reactor and is calculated during preparations to reload a reactor, but the actual burnup profile is not measured. The axial burnup profile is important to the determination of the reactivity of a waste package, so a conservative evaluation of the calculated axial profiles for a large database of SNF has been performed. The product of the axial profile evaluation is a profile that is conservative with respect to reactivity. Thus, there is no need for physical measurement of the axial profile.

Procedural safety controls provide assurance that the correct assembly is loaded into each waste package. DOE will also employ probabilistic analyses to show that procedural safety controls can minimize the chance of a misload but not completely eliminate this risk (BSC 2003b). 


\section{Source Of Burnup Values For Commercial Spent Nuclear Fuel Assemblies}

\section{Reactor Record Assigned Burnup}

The assigned burnup is the appropriate source of burnup for use in waste package loading decisions utilizing criticality loading curves. With appropriate determination and incorporation of the burnup value uncertainties into the criticality loading curves, the reactor record assigned burnup provides the most reliable burnup value.

A commercial power reactor is monitored by a number of detectors that allow measurement of the radial and axial variations of the power produced by the reactor core. The total power produced by the core is tracked as a function of time by means of the core heat output. These measurements are coupled with "core follow" calculations in order to establish the burnup of each assembly when the core is reloaded every twelve to twenty-four months. These are the reactor record burnup values, which are then used in the design of the new core for the next cycle of operation of the reactor. Before the refueled reactor is allowed to reach a significant power level, a startup physics test is performed to verify that each assembly is loaded in the correct position and has the burnup that was calculated for it. Anomalous behavior of the reactor control system in an area of the core indicates an assembly that does not contain the determined burnup, and the condition must be evaluated and the assemblies are moved if necessary. The startup physics testing thus verifies the burnup of each assembly in the core at the time of the restart of each of the approximately 100 power reactors in the U.S.

The Electric Power Research Institute studied reactor record uncertainties in the Determination of the Accuracy of Utility Spent-Fuel Burnup Records (EPRI 1999) using a limited sample of reactor records. EPRI concluded that the uncertainty associated with current plant core follow burnup values (for assemblies from multiple core reloads of a single Westinghouse PWR) is less than 2 percent, i.e. the percentage difference between the burnup values calculated by reactor core power distribution models and the burnup measured by calibrated in-core detectors. Further evaluation using the EPRI methodology (Massie 2004) has been conducted for a larger sample population of industry data consisting of 5,447 fuel assemblies having an end-of-cycle burnup of greater than $10,000 \mathrm{MWd} / \mathrm{MTU}$ from nine PWR plants. This evaluation found uncertainties in the range of 2 to 5 percent at a 95/95-confidence level. The upper bound of this range is expected to decrease for newer plants and fuel loads as the population of data increases. For older fuel assemblies and plants, the uncertainty is expected to be no greater than 5 percent. Criticality loading curves account for the uncertainty associated with the utility assigned burnup values by adding a five-percent margin to the burnup values on the curve.

A potential problem in using assigned burnup values arises because, in the past, utilities have been allowed to group several assemblies with similar characteristics, called a batch, into a single record for the purposes of reporting fuel inventories to the NRC. A recent scoping examination of utility records (O'Leary 2001) for Three Mile Island Unit 1 and plant core follow burnup values produced mixed results. This examination involved 12 discharged reloads of fuel, representing approximately 740 fuel assemblies. About twothirds of the reported assembly burnups agreed well with the measured burnup values. About one-third of the reported burnups reflected batch average values rather than 


\section{Source Of Burnup Values For Commercial Spent Nuclear Fuel Assemblies}

individual assembly burnup values. The differences were generally between $+5,000$ $\mathrm{MWd} / \mathrm{MTU}$ and $-5,000 \mathrm{MWd} / \mathrm{MTU}$; with maximum differences upwards of $-16,000$ $\mathrm{MWd} / \mathrm{MTU}$ for some assemblies. Figure 1 shows the differences between measured and reported assembly burnups.

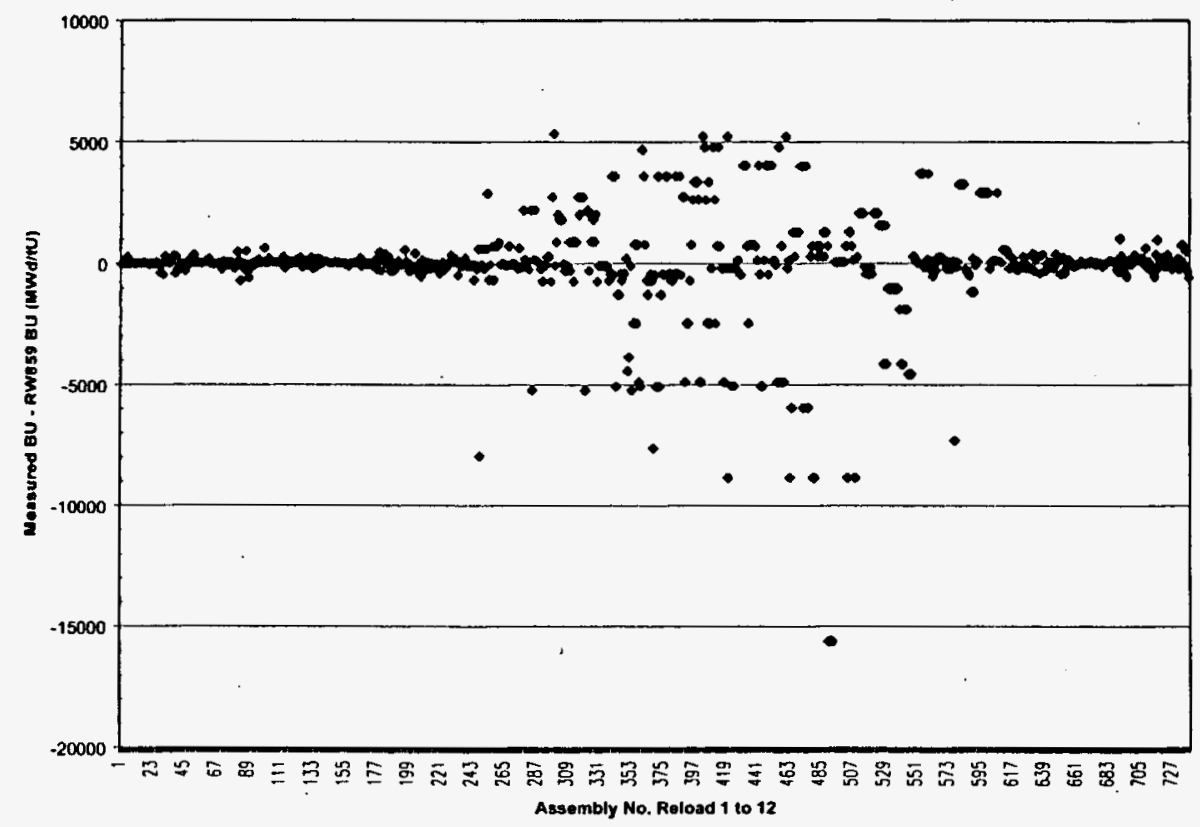

Source: O'Leary 2001

Figure 1. Comparison of Measured - Reported Assembly Burnups

Utilities normally are able to retrieve the reactor core follow data so that assembly specific burnup values can be assigned. If the assigned burnup is a batch average value and core follow data are not available, then a margin of $5000 \mathrm{MWd} / \mathrm{MTU}$ is added to the criticality loading curve calculation to account for the uncertainty of the batch average value.

Adjustment of the criticality loading curves for the burnup uncertainties is preferable to adjustment of individual assembly assigned burnup values on the basis of operational complexity. Interim (NRC) Staff Guidance - 8, Revision 2. Burnup Credit in the Criticality Safety Analyses of PWR Spent Fuel in Transport and Storage Casks (NRC $2002 \mathrm{~b}$ ), Recommendation 5, applies the uncertainty on an assembly-by-assembly basis. However, the adjusted criticality loading curve approach is preferable for the waste package loading operations as it requires fewer data manipulations, and presents far fewer opportunities for introducing human errors. For this approach, a criticality loading curve adjusted for assigned burnup uncertainty is generated once, and the assigned burnup values of all received commercial SNF assemblies are compared directly against this criticality loading curve.

Figure 2 presents a flow chart that illustrates the relationships between the various possibilities of assigned burnup values and the actions that can be taken to safely load the SNF into the appropriate waste package. The assigned burnup is provided by utility 


\section{Source Of Burnup Values For Commercial Spent Nuclear Fuel Assemblies}

records, and the data available from the utility allow the burnup values for a given discharge date to be inspected. If assigned burnup values repeat in groups, then it is apparent that batch average burnup values were provided by the originating utility. The presence of batch average burnup values is known to the utility in any case, so batch average data are always identifiable.

Assembly specific utility assigned burnup values are preferable for waste package loading, because if the data provided are assembly specific, then the waste package can be loaded without further data review. The criticality loading curve is already adjusted for the uncertainty in assembly specific burnup, so no action is required.

If batch average assigned burnups are provided, then the preferred course of action is to obtain or calculate the assembly specific burnup values. If the utility records contain the assembly specific burnup values in an accessible form, then these values should be used as the assigned burnups. If not, then calculation of assembly specific burnup values is possible through the use of reactor physics core-follow computer codes. These computer codes are used by reactor vendors to calculate the burnup of every assembly in a reactor core over a period of operation during normal fuel reloading operations. Calculation of assembly specific values could be expensive, so a cost/benefit analysis of the effort may be employed. Once assembly specific burnup values are recalculated and assigned to the $\mathrm{SNF}$, loading of waste packages may progress in the standard fashion.

If the assembly specific burnup value calculation is too difficult or cost prohibitive, waste packages may still be loaded based on the batch average burnup values. In this case, an additional margin to account for the uncertainty introduced by the averaging procedure is included into an adjusted criticality loading curve. This additional margin may prevent loading of all of the assemblies in a group of shipments, and use of special waste packages with extra criticality control measures (such as reduced waste package capacity or adding disposal control rod assemblies) may be necessary.

If there are unresolved issues with an assigned burnup, a commercial SNF PWR assembly can still be loaded into the special package configuration that includes surrogate disposal control rod assemblies inserted into the assembly guide tubes or a reducedcapacity package with blocked out fuel cells. A BWR assembly could be loaded into a lower-capacity BWR waste package with stronger criticality control built into the fuel support basket.

All assemblies can be accommodated by the combination of these options, so the alternative of performing a physical burnup measurement prior to loading a waste package is not required.

To facilitate the handling and control of each fuel assembly and waste package, a Loading Plan developed in advance of each transportation cask shipment to the repository that defines each handling step from time of receipt at the repository to final emplacement. Prior to SNF arriving at the repository, a number of information exchanges take place between the repository and the utilities. These information exchanges allow the repository operators to prepare loading plans. The loading plans will address the burnup record issues, including identifying which criticality loading curves and waste packages will be used for a given fuel assembly. 
Source Of Burnup Values For Commercial Spent Nuclear Fuel Assemblies

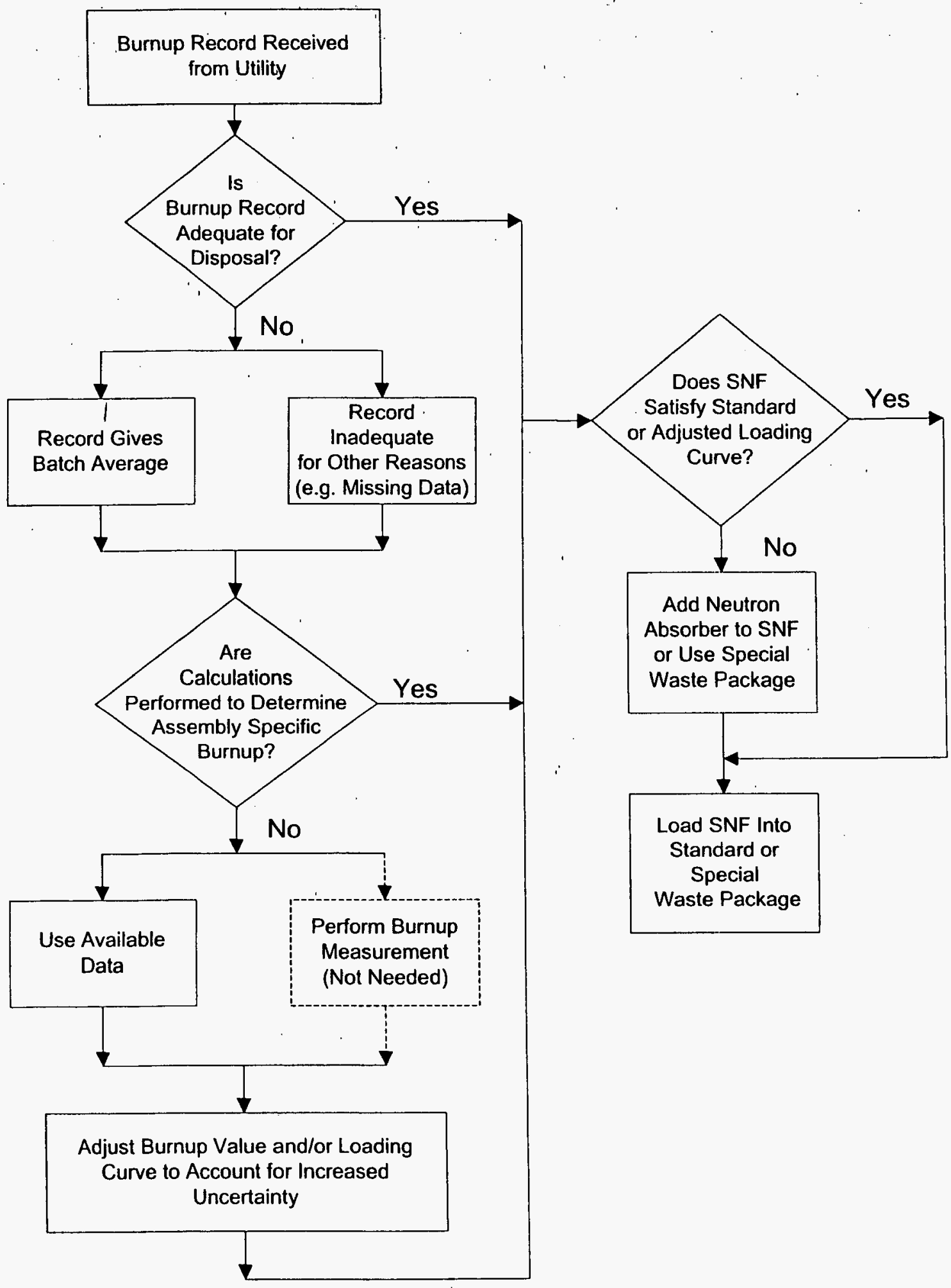

Figure 2. Use of Assigned Burnup for Loading Operations 


\section{Source Of Burnup Values For Commercial Spent Nuclear Fuel Assemblies}

\section{Axial Burnup Profile}

Axial power and the fuel burnup vary along the length of fuel rods; in most cases diminishing near the less exposed ends of the rods. The positive reactivity effect caused by the diminished burnup at the SNF assembly ends is referred to as the "end effect". Recommendation 3 of Interim Staff Guidance - 8, Revision 2. Burnup Credit in the Criticality Safety Analyses of PWR Spent Fuel in Transport and Storage Casks (NRC 2002b) states in part that "Of particular concern should be: a.) the need to account for and effectively model the axial ... variation of the burnup within a spent fuel assembly...". The repository methodology (YMP 2003) accounts for axial burnup effects through the selection of conservative (with respect to reactivity) isotopic concentrations and/or profiles. Application of the methodology involves selecting conservative axial burnup profiles using a statistical process (BSC 2003a, BSC 2004a). The conservative profile changes as a function of burnup, so a set of axial burnup profiles is provided to cover a range of burnup values. Application of this methodology then incorporates the selection of depletion parameters that increase reactivity in the waste package. The methodology ensures a $95 \%$ confidence that the burnup is conservative for $95 \%$ or more of the axial burnup values, and the reactivity is conservative. The conservative isotopic concentrations produced with the conservative burnup profiles are used in the criticality loading curve evaluations.

Figures 3, 4, and 5 illustrate the process of determining axial parameters that are required for BWR SNF in criticality loading curve evaluations. These parameters are used in the calculations of conservative isotopic inventory and represent conditions present in the reactor core as the fuel was burned. The BWR database of reactor records was statistically analyzed to determine the average and minimum burnup values as a function of axial position. The axial profiles are presented as curves with values for axial segments, or nodes. In Figure 3, the bottom end of the fuel assembly is node one, and the top end is node ten. A conservative profile for criticality loading curve evaluations is produced by using the lower $95 \%$ confidence limit values at the top and bottom ends of the assembly, while the center section of the fuel is adjusted upward to conserve the total burnup. Thus the burnup at the ends is at or near the minimum to maximize the axial "end effects" that are a concern for waste packages.

Figure 3 illustrates the BWR axial burnup. PWR SNF follows a similar curve. In addition to the burnup axial profile requirement, BWR SNF requires the determination of the axial values for moderator density. These values are not required for PWR SNF because the PWR moderator density does not vary significantly with axial position. 


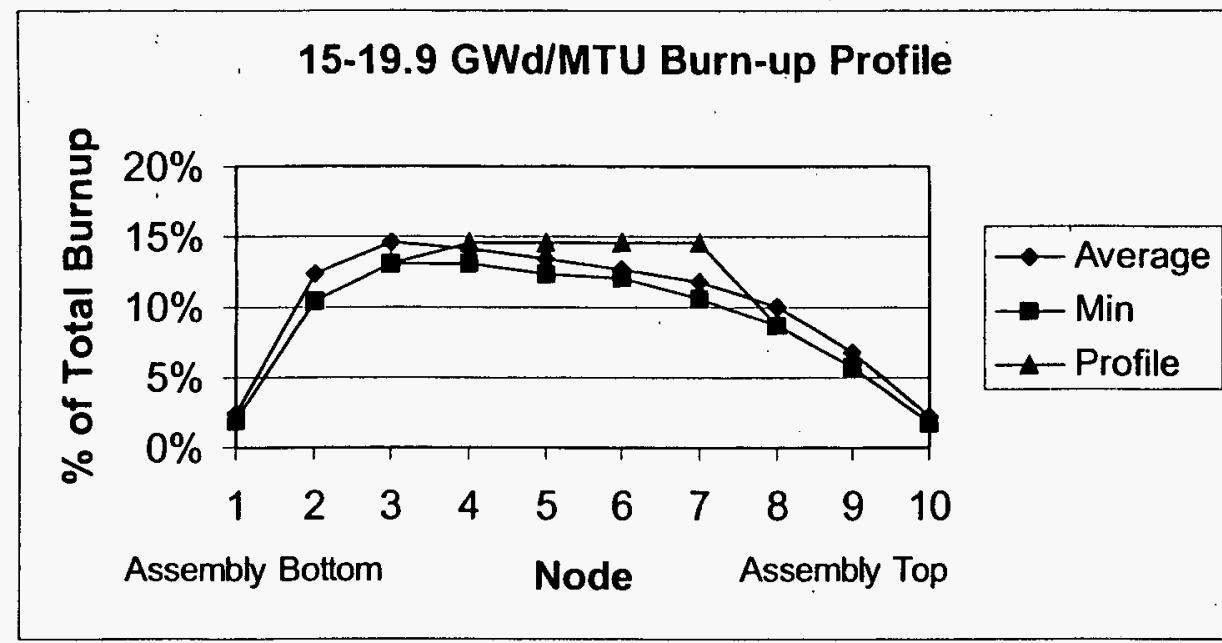

Notes:

BWR Bumup Profile Data for Grand Gulf

Source: BSC 2004a

Average at each of 10 Axial Nodes shown

Minimum values are also shown

Profile is Average Minus $2 \sigma$ at Bottom (Inlet) and Top Three Nodes, Normalized to Preserve Burnup at Center Nodes

Figure 3. Axial Burnup Profile for BWR fuel

The SNF assembly is broken into axial segments with burnups obtained from the conservative axial profile. Isotopic concentrations are calculated for each axial segment, and a composite three-dimensional representation of the isotopics and geometry of the fuel assembly is used by MCNP to calculate a conservative $\mathrm{k}_{\text {eff. }}$

Figure 3 shows that the statistically derived profile is at or near the minimum burnup value at the top and bottom end nodes, so that the axial end effect is conservatively represented. The burnup in the central portion of the fuel assembly is adjusted to preserve the total assembly burnup.

Figures 4 and 5 show the axial variation of parameters that are important to the calculation of conservative BWR SNF isotopic contents.

Figure 4 illustrates the moderator density profile for the BWR assembly. The moderator density is obtained from the BWR reactor record database. The average moderator density profile is provided and the minimum moderator density is also shown.

Figure 5 illustrates the fuel pellet temperature profile for the BWR assembly. The fuel temperature is not as strong an effect as the effect of moderator density, but must be considered. 
Source Of Burnup Values For Commercial Spent Nuclear Fuel Assemblies

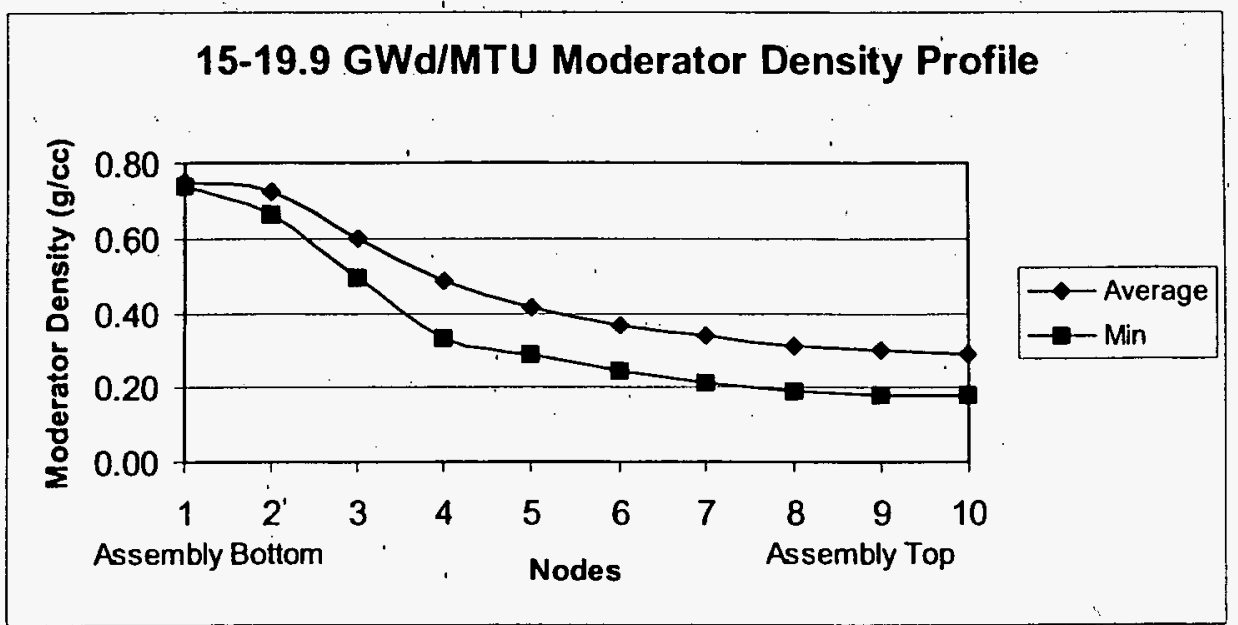

Notes:

Source: BSC 2004a

B WWR Moderator Density Profile for Grand Gulf, Quad Cities, LaSalle

Mean Value of Average Density is $0.43 \mathrm{~g} / \mathrm{cc}$

Mean Value of Minimum Density is $0.30 \mathrm{~g} / \mathrm{cc}$

Profile shown is Minimum, but Mean minus $2 \sigma$ is used in calculations

Figure 4. BWR Moderator Dẹnsity Profile

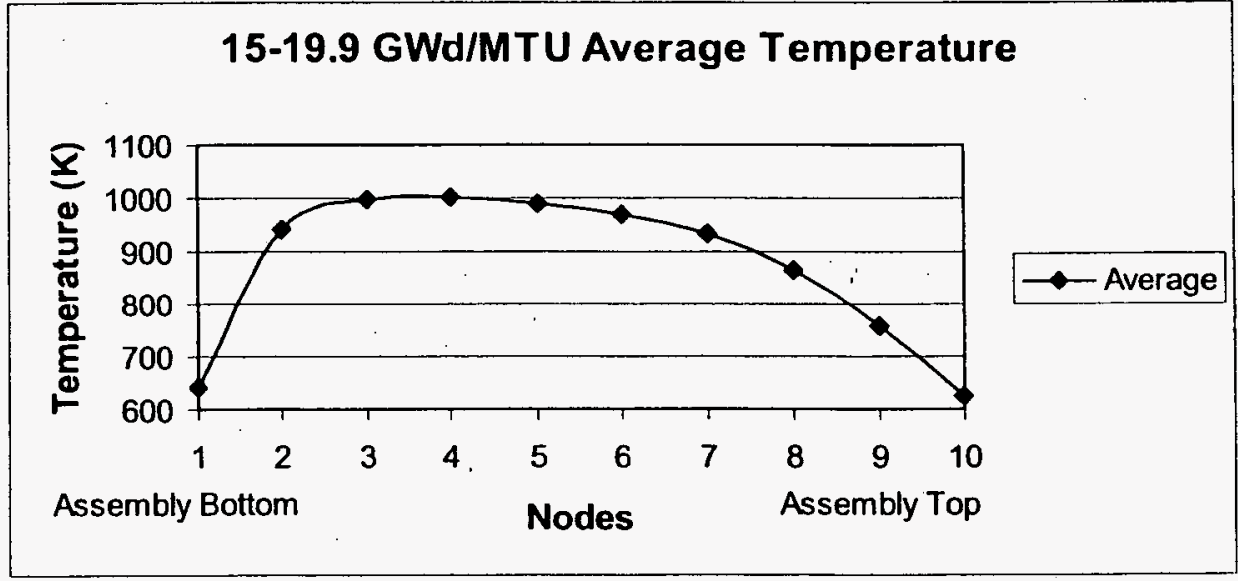

Notes:

Source: BSC 2004a

BWR Temperature versus Height for Grand Gulf, Quad Cities,

LaSalle Node Average Temperature is shown

Temperatures are nearly constant with height as void fraction changes until mixing at top causes decrease. Note that PWR temperatures increase monotonically with height.

Figure 5. BWR Fuel Pellet Temperature Profile 


\section{Source Of Burnup Values For Commercial Spent Nuclear Fuel Assemblies}

\section{Waste Package Misload}

Waste package misload is a credible preclosure event in the repository surface facility as indicated in Commercial Spent Nuclear Fuel Waste Package Misload Analysis (BSC 2003b). A misload of a: waste package could occur due to YMP surface facility operational errors or as the result of utility shipping errors. The analysis determines a probability of one or more misloading events occurring considering available human reliability factors associated with representative operations (NUREG/CR-1278, Swain and Guttmann 1983).

A misload might occur during the loading process prior to closure of the repository, and become a pre-existing condition for events during the postclosure time period. The probability of a misload event is considered in the criticality features, events, and processes (FEPs) screening analysis for postclosure. The probability of a misload event increases the probability of criticality for configurations that are otherwise not critical.

Waste handling procedural safety controls include considerations for minimizing the potential for misloading errors. The principal procedural safety control is to confirm with an independent check that the assembly being loaded into a waste package has the proper assembly identifier, so that the conformance of the assigned fuel assembly burnup value to the criticality loading curve can be verified.

There are two types of misloads to consider: loading the wrong assemblies into a waste package and loading assemblies into the wrong waste package. In the first case, the assemblies could be "wrong" for a waste package because their assigned burnup was less than the value required by the criticality loading curve. Such "underburned" SNF could reduce the criticality safety margins but would not result in an actual criticality event (BSC 2004b). The probability of one such misload over the entire preclosure period is calculated to be 0.23 for the $95^{\text {th }}$ percentile with independent checking of assembly data as an operational control. In the second case, SNF intended for a 21-PWR Absorber Plate waste package could be misloaded into a 21-PWR Control Rod waste package, but without the control rods installed in the SNF. The probability of one such misload over the entire preclosure period is calculated to be 0.005 . It should be recalled that the waste package must be flooded before a potential criticality situation can exist, and moderator control in the surface facility and the welded configuration in the subsurface facility assures criticality safety prior to repository closure.

For preclosure operations, procedural safety controls (independent checking) are implemented to lower the probability of misload. The conservative methodologies used to determine the criticality loading curve for a waste package provide sufficient margin so that criticality safety is assured for preclosure operations even in the event of a misload.

The potential for criticality due to misload events is accounted for in postclosure by the FEPs screening analysis. Waste form misload events are included in the criticality FEPs screening analysis event trees (BSC 2004c). The misload per waste package probability value used in the event trees for the 21-PWR waste package is $1.18 \times 10^{-5}$ and for the 44BWR waste package is $1.73 \times 10^{-5}$. 


\section{Source Of Burnup Values For Commercial Spent Nuclear Fuel Assemblies}

\section{Summary}

The approach to application of burnup credit to criticality analyses involves:

1. Using reactor records as the basis of commercial SNF burnup values for disposal criticality analyses.

2. Accounting for the uncertainty in burnup values through conservative criticality loading curve adjustments rather than by adjustments to assigned burnup values.

3. The effect on criticality of non-uniform axial burnup of the spent fuel assembly is accommodated by calculations that use conservative axial burnup profiles based on statistical analyses.

4. Procedural safety controls (independent checking) are implemented to reduce the probability of misload. The conservative methodologies used to determine the criticality loading curve for a waste package provide sufficient margin so that criticality safety is assured for preclosure operations even in the event of a misload.

5. The potential for criticality due to misload events is accounted for in postclosure by the screening analysis for criticality features, events, and processes.

The methods described above provide solutions to the issues regarding assigned burnup, axial burnup profile, and misload. These methods ensure that the criticality loading curves for waste packages are conservative and that criticality safety is assured. 


\section{Source Of Burnup Values For Commercial Spent Nuclear Fuel Assemblies}

\section{References}

BSC (Bechtel SAIC Company) 2003a. PWR Axial Burnup Profile Analysis. CAL-DSUNU-000012 REV 00A. Las Vegas, Nevada: Bechtel SAIC Company. ACC: DOC.20031002.002.

BSC 2003b. Commercial Spent Nuclear Fuel Waste Package Misload Analysis. CALWHS-MD-000003 REV 00A. Las Vegas, Nevada: Bechtel SAIC Company. ACC: DOC.20031002.0005.

BSC 2004a. BWR Axial Profile. CAL-DSU-NU-000005 REV 00A. Las Vegas, Nevada: Bechtel SAIC Company. ACC: DOC.20040927.0039.

BSC 2004b. 21-PWR Waste Package with Absorber Plates Loading Curve Evaluation, Las Vegas, Nevada; Bechtel SAIC Company: ACC: DOC.20040922.0004.

BSC 2004c. Screening Analysis for Criticality Features, Events, and Processes for License Application. ANL-EBS-NU-000008 REV 01. Las Vegas, Nevada: Bechtel SAIC Company. ACC: DOC.20041022.0001.

EPRI (Electric Power Research Institute) 1999. Determination of the Accuracy of Utility Spent-Fuel Burnup Records. EPRI TR-112054. Palo Alto, California. Electric Power Research Institute. TIC: 254706.

Massie, H.L., Jr. 2004. Reactor Record Uncertainty Determination. 32-5041666-02. Las Vegas, Nevada: Areva. ACC: DOC.20040623.0002.

NRC (U.S. Nuclear Regulatory Commission) 1998. Regulatory Guide 3.71. Nuclear Criticality Safety Standards for Fuels and Material Facilities. Washington, D.C.: U.S. Nuclear Regulatory Commission. Readily available.

NRC 2002a. Integrated Issue Resolution Status Report. NUREG-1762, Rev. 0. Washington, D.C.: U.S. Nuclear Regulatory Commission, Office of Nuclear Material Safety and Safeguards. ACC: MOL.20021010.0296.

NRC 2002b. ISG-8 - Burnup Credit in the Criticality Safety Analyses of PWR Spent Fuel in Transport and Storage Casks. Interim Staff Guidance-8, Revision 2. Washington, D.C.: U.S. Nuclear Regulatory Commission.

O'Leary, P. 2001. "Final Draft of BUV White Paper." E-mail from P. O'Leary to D. Salmon and D. Thomas, January 18, 2001, with attachment. ACC: MOL.20010313.0307.

Reamer, C.W. 2000. "Safety Evaluation Report for Disposal Criticality Analysis Methodology Topical Report, Revision 0." Letter from C.W. Reamer (NRC) to S.J. Brocoum (DOE/YMSCO), June 26, 2000, with enclosure. ACC: MOL.20000919.0157.

Reamer, C.W., and Gil, A.V 2001. Summary Highlights of NRC/DOE Technical Exchange and Management Meeting on Pre-Closure Safety. Meeting held July 24-26, 2001, Las Vegas, Nevada. Washington, D.C.: U.S. Nuclear Regulatory Commission. ACC: MOL.20011003.0091. 
Swain, A.D. and Guttmann, H.E. 1983. Handbook of Human Reliability Analysis with Emphasis on Nuclear Power Plant Applications Final Report. NUREG/CR-1278. Washington, D.C.: U.S. Nuclear Regulatory Commission. TIC: 246563.

YMP (Yucca Mountain Site Characterization Project) 2003. Disposal Criticality Analysis Methodology Topical Report: YMP/TR-004Q, Rev. 02. Las Vegas, Nevada: Yucca 